\title{
UN TEXTO DE LOPE DE RUEDA: MADRIGALEJO, MOLINA Y EL ALGUACIL EN EL PASO CUARTO DEL REGISTRO DE REPRESENTANTES
}

\section{IGNACIO ARELLANO GRISO (Universidad de Navarra)}

En el paso cuarto del Registro de representantes de Lope de Rueda (publicado en Valencia, 1570, por Joan Timoneda), conocido habitualmente por el título de Los lacayos ladrones, que le dio Cayetano Alberto de la Barrera, ${ }^{1}$ hay un pasaje que viene planteando sistemáticamente una serie de problemas a los editores modernos, sin que hasta la fecha, que yo conozca, esté completamente dilucidado.

La estructura básica del paso es un diálogo entre Madrigalejo, Molina y un Alguacil (también aparece un paje en escena). El primero es un ladronzuelo-no consta que sea lacayo ${ }^{2}$-, que aparece en escena echando fieros y amenazas contra alguien que supuestamente le ha ofendido:

¡Reñego del gran Taborlán y de todos sus consortes y bien allegados, y de toda la canalla que rige y gobierna la infernalísima barca del viejo carcomido Carón, que si entre las manos le tomo ad aquel que semejante palabra y afrenta de la boca se le soltó, si a puros papirotazos no le convierto el pellejo en pergamino virgen!

Por lo que sigue sabemos que a Madrigalejo lo han sorprendido mientras intentaba robar una bolsa y lo han rechazado con rudas maneras, lla- 
mándolo seguramente ladrón (que debe de ser la palabra afrentosa de la que se queja en su alegato).

Molina ha presenciado el altercado y entabla conversación con Madrigalejo («Por cierto, ello fue palabra muy mal sonante, señor Madrigalejo»). El ladrón pregunta a su interlocutor el nombre y patria y sigue un diálogo en el que se recuerdan algunas aventuras de Madrigalejo, entre ellas un castigo que recibió en la ciudad de Granada, de donde es Molina, y que este recuerda haber visto cinco años atrás. Molina, por tanto, tiene alguna referencia de Madrigalejo, aunque su condición simplona no alcanza a protegerlo de una relación inconveniente y parece mostrar una actitud amistosa hacia el pícaro, que solo le traerá problemas.

En efecto, la conversación se interrumpe con la llegada de un alguacil acompañado de un paje, que vienen en busca del ladrón. Madrigalejo pide a Molina que le guarde un lío que trae y que abone su persona certificando que lo conoce y que es hombre de bien. Molina, el tonto, acepta.

En el interrogatorio se descubre que a Madrigalejo le faltan las orejas, castigo habitual para los ladrones, pero él lo achaca disparatadamente a una herida recibida en la batalla de San Quintín, de la que trae testimonios, como los soldados, según afirma. El aguacil le solicita ver los testimonios y Madrigalejo, que sin duda trae una serie de papeles falsos en su faltriquera, saca un papel y lo entrega al alguacil.

Este es el pasaje controvertido. En la edición de Timoneda, la primera y fuente de las posteriores, el texto es como sigue:

ALGUACIL.- Enseñá.

MADRIGALEJO.- Tome, señor.

ALGUACIL.- Señor Madrigal, hágame merced de venirse hacia l'Antigua, porque hagamos partición de aquella bolsa que sangramos a la frutera.

ALGUACIL.- ¿Barbero sois de bolsas? ¡Teneldo bien! Y a esotro mirad lo que lleva debajo la capa.

El texto, según acabo de transcribir, parece haber sufrido una deturpación que los editores modernos intentan subsanar con variadas soluciones. Tal como se lee en la príncipe el alguacil tendría dos intervenciones seguidas y además se dirige a Madrigal reconociendo su complicidad en un robo hecho a una frutera. La reacción que expresa la intervención 
siguiente del mismo alguacil carece de sentido también con esta lectura.

¿Cómo se han enfrentado los distintos editores a este pasaje?

La opción más simple es imprimirlo como en la príncipe sin ninguna otra indicación ni hacerse ningún problema. En la edición de Taurus con prólogo de García Pavón (120), se mantiene el texto tal como lo imprime Timoneda, sin observación alguna. La mayoría de los editores reparan, sin embargo, en la dificultad, pero yerran a menudo en las soluciones, seguramente por no tener en cuenta la escenificación del paso, y atenerse al texto escrito, que es menos revelador que la representación.

$\mathrm{Si}$ consideramos que el alguacil no puede pronunciar las dos intervenciones seguidas, ${ }^{3}$ se abren dos posibilidades de enmienda, con diversos matices. Las dos enmiendas básicas consisten en atribuir el parlamento «Señor Madrigal, hágame merced de venirse hacia l'Antigua, porque hagamos partición de aquella bolsa que sangramos a la frutera», bien a Madrigalejo, bien a Molina.

La edición de Iberoamericana de Publicaciones (1928, p. 88) atribuye el parlamento a Madrigalejo, lo cual provoca una segunda enmienda en el texto del mismo, cambiando "Señor Madrigal». por «Señor [Molina]», pues Molina habría de ser en este caso el destinatario: el pasaje queda, entonces:
ALGUACIL.- Enseñá.
MADRIGALEJO.- Tome, señor.
[MADRIGALEJO].- Señor [Molina], hágame merced de venirse hacia l'Antigua, porque hagamos partición de aquella bolsa que sangramos a la frutera.
ALGUACIL.- ¿Barbero sois de bolsas? ¡Teneldo bien! Y a esotro mirad lo que lleva debajo la capa.

Con esa lectura es Madrigalejo el que habla dos veces seguidas. Podría aceptarse, pero entonces su comentario a Molina debería ser hecho aparte, porque no tiene sentido que se denuncie en voz alta ante el aguacil hablando de un robo. Por lo demás es absurdo de todo punto que en la situación en que se hallan se ponga a ajustar un encuentro para repartirse los dineros de una bolsa robada, ${ }^{4}$ como si no hubiese encontrado otro momento más oportuno. Esta solución, sin embargo, es la elegida en una de las mejores ediciones de los pasos de Rueda, la de González Ollé y Tusón. Dándose cuenta de que el comentario de la bolsa de la frutera no 
debe ser oído por el alguacil, lo señalan como aparte y apuntan la siguiente explicación:

Por error, el aparte que sigue, entre paréntesis, se atribuye al ALGUAZIL, en el original. Es evidente, por el desarrollo de la acción, que se trata de palabras de Madrigalejo a Molina. ${ }^{5}$ De ahí también la corrección que se consigna en la nota siguiente. (197)

La nota siguiente explica que se ha cambiado el nombre de «Madrigal» por el de «Molina», como ya se ha visto.

Pero la reacción del alguacil («¿Barbero sois de bolsas?») demuestra que lo anterior no ha sido un aparte, o que si quería ser un aparte no ha tenido éxito, pues el alguacil se ha enterado perfectamente del asunto de la bolsa.

Repasando otras ediciones de Rueda vemos que la solución que acabo de comentar es la preferida también por Juan María Marín (128), quien reproduce exactamente el texto y da la misma explicación que González Ollé-Tusón. Es asimismo la elegida en la excelente traducción de Enrica Cancelliere:

GUARDIA.- Mostratemelo.

MADRIGALEJO.- Eccolo signore. (sottovoce a Molina). Signor Molina, fatemi il favore di dirigervi verso la chiesa

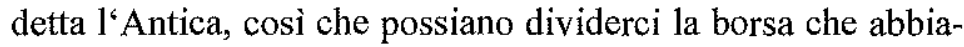
mo rubato alla frutivendola.

GUARDIA.- Ah, un tagliaborse! Fermatelo, e a quest'altro controllate cosa nasconde sotto il mantello. (151)

Y en la nota 10 de esa página 151 , Cancelliere comenta:

Seguiamo l'interpretazione di alcuni commentatori, che attribiuscono questa battuta a Madrigalejo. Il che risulta anche possibile se consideriamo che, da quando è iniziato il dialogo con la guardia, è stato sempre Madrigalejo a tirare in ballo il compare Molina.

La segunda opción, que es atribuir el parlamento a Molina, es la segui- 
da por otras ediciones. En la de Obras de Lope de Rueda de la Real Academia Española (II, 287) se mantiene sin enmendar el texto príncipe, pero se hace notar que hay un error en la atribución al alguacil del parlamento que empieza «Señor Madrigalejo»: «Así en el original, pero claro es que debiera decir MOLINA». Su solución sería, pues, atribuir a Molina ese fragmento que va dirigido a Madrigal: el razonamiento subyacente es que si el parlamento va destinado a Madrigal (no considera defectuoso ese detalle) y no lo puede pronunciar el alguacil, solo lo puede pronunciar Molina (el cual se convierte en ladrón porque sí, por la influencia seguramente del mal título propuesto por de la Barrera). A Molina lo atribuyen Sáinz de Robles (161-62) y Cardona (642). Ninguno de los editores que optan por la atribución a Molina señala aparte, lo cual explica la reacción del alguacil (que evidentemente se ha enterado del asunto de la frutera robada), pero deja por explicar las razones por las cuales unos ladrones se pondrían a hablar de sus robos delante de un alguacil cuando este los está deteniendo.

La edición de Canet me parece que es la que da con la buena solución conservando la atribución única al alguacil, pero añadiendo la acotación «Lee» para el segundo de los parlamentos (176). Me parece, no obstante, que en el marco de las dificultades expuestas, merece la pena completar la nota de Canet $^{6}$ con algunas consideraciones más detenidas para justificar lo que me parece es el texto auténtico de Lope de Rueda.

Se pueden hacer varias precisiones relativas al lugar textual en cuestión y otras que afectan a la interpretación general del paso entero:

1. El título de Los lacayos ladrones no es apropiado y provoca malos entendimientos de la pieza. Solo es ladrón Madrigalejo. En ningún momento se dice que lo sea Molina, salvo en las malas enmiendas textuales ofrecidas por diversos editores y que hay que desechar. Sería un mejor título Paso del ladrón, el simple y el alguacil.

2. Si examinamos la relación entre los personajes se observa que Madrigalejo se burla siempre de Molina, que es un simple. Madrigalejo no conoce a Molina antes de la acción: le pregunta su nombre y procedencia. ${ }^{7}$ No hay ninguna complicidad para el robo de la bolsa de la frutera ni para ningún otro robo. Molina, por su lado, conoce a Madrigalejo de vista y de nom- 
bre: recuerda el castigo granadino que sufrió Madrigal y acaba de presenciar el altercado en la plaza. Como es bastante bobo entabla amistosa conversación con un personaje poco recomendable, pero no se puede inferir que haya una relación previa. Carece de sentido la supuesta cita entre ambos en la iglesia de la Antigua para repartir ningún botín. Esto hace impertinentes las atribuciones del parlamento segundo tanto a Molina como a Madrigalejo. Ninguno de los dos puede pronunciarlo.

3. El parlamento pronunciado es el de un testimonio escrito que figura en un papel. Si se imagina la escena representada el pasaje se aclara por sí solo: casi todos los editores olvidan el papel y creen que el pasaje se trata de un parlamento hablado normal. ${ }^{8}$ En efecto, ese papel de Madrigal estaba escrito previamente a la acción representada en la actualidad del paso. Otro motivo más para desechar que su destinatario sea Molina, al cual Madrigal no conocía de nada. La enmienda del nombre del destinatario (Madrigal por Molina) es inaceptable.

4. El papel está en manos del alguacil. Madrigalejo se ha debido de equivocar de papel, porque no es creíble que quisiera darle al alguacil una nota incriminatoria. Seguramente quería darle un testimonio falsificado de hazañas militares, ${ }^{9}$ pero el caso es que le da una nota de un cómplice ladrón. La acotación de Canet es muy pertinente. Al leer el alguacil el mensaje le queda completamente claro que Madrigal es un ladrón y manda al paje que lo sujete para llevarlo detenido. Todas las enmiendas propuestas son impertinentes, pues no explicarían la reacción del alguacil. Molina, que por bobo ha venido abonando a Madrigal y le ha guardado imprudentemente el lío, se verá incriminado, aunque no ha robado nada.

5. El texto hablado por el alguacil reproduce una nota escrita dirigida por un ladrón a otro. Es lógico que el papel lleve el nombre de su destinatario, Madrigal, luego no hay que cambiar por Molina el nombre que figura en el mensaje. Madrigal es lo correcto. ¿Quién lo ha escrito? Un ladrón innominado, cómplice de Madrigal en el robo de la frutera, que cita a Madrigal en la Antigua para repartirse los dineros. 
En conclusión, el texto de la príncipe es el correcto, no necesita ninguna enmienda, aunque el añadido de la acotación que propone Canet puede ayudar a la mejor comprensión de la escena. Debería imprimirse así:
ALGUACIL.- Enseñá.
MADRIGALEJO.- Tome, señor.
ALGUACIL.- [Leyendo.] «Señor Madrigal, hágame merced de venirse hacia l'Antigua, porque hagamos partición de aque- lla bolsa que sangramos a la frutera». ¿Barbero sois de bolsas? ¡Teneldo bien! Y a esotro mirad lo que lleva debajo la capa.

Sin duda, Timoneda tenía en cuenta la visualización de la escena cuando imprimía los textos teatrales, y no consideraba necesario añadir indicaciones que desde la imaginación escénica no hacían falta.

\section{NOTAS}

I. Es un mal título, como indicaré más adelante, y quizá causa parcial del malentendido con este pasaje de la pieza, al sugerir la idea de un diálogo entre ladrones.

2. Ni en el sentido habitual de lacayo 'mozo de espuelas', ni en el de 'soldado de infantería' o 'bandolero' que aparece en algunos textos, como se indica en la edición de González Ollé-Tusón, hay datos en el texto para atribuir a Madrigalejo (ni a Molina) la condición de lacayos, que no parece relevante en la pieza.

3. La segunda es obviamente del alguacil, que ordena al paje que detenga a Madrigalejo y mire lo que Molina Ileva debajo de la capa.

4. Hay más dificultades para esta propuesta, que comentaré después.

5. Veremos enseguida, con más argumentos, otra posibilidad.

6. «Ën la edición de los Pasos de Fernando González Ollé y Vicente Tusón, la lectura del papel la hace el propio personaje de Madrigalejo: asimismo el nombre de Madrigalejo que aparece en la carta ha sido modificado por el de Molina. Prefiero mantener la versión original puesto que es el personaje de Madrigalejo quien da el papel al Alguacil».

7. «MADRIGALEJO.- ¿[...] ¿Cómo es su gracia, señor? MOLINA.- Señor, Molina, para su servicio. MADRIGALEJO.- ¿Es bien, señor Molina, que digan de mí semejantes palabras? ¿Hombre era yo que le había d'escalfar su bolsa? ¿Faltábanme a mí dos pares de reales entre amigos? MOLINA.${ }_{\text {} P}$ Por Dios, señor! Yo no creo tal, y pésame de que vi que os trataban mal y acudían tantos contra vos. 
MADRIGALEJO.- ¿De dónde bueno es vuestra merced, sefror Molina? MOLINA.- Señor, de Granada).

8. Pero no es así: ¿dónde habría ido a parar el papel que pide el aguacil entonces? Ese parlamento es precisamente lo que está escrito en el papel: si en vez de leer el paso lo estuviéramos viendo no habría ningún problema de entendimiento.

9. El falso soldado que presume de falsas hazañas es personaje tópico de la literatura satírica y picaresca.

\section{EDICIONES CITADAS DE LOPE DE RUEDA}

Obras de Lope de Rueda. Ed. E. Cotarelo. Tomo II. Madrid: Real Academia Española, 1908. Registro de representantes. El Deleitoso. Madrid: Copañ́a Iberomericana de Publicaciones, 1928. Pasos completos. Nota preliminar de F. Sáinz de Robles. Madrid: Aguilar, 1944.

Pasos completos, Prólogo de F. García Pavón. Madrid: Taurus, 1966.

Teatro completo. Ed À. Cardona. Barcelona: Bruguera, 1967, 1979.

Pasos. Ed. F. González Ollé y V. Tusón. Madrid: Cátedra, 1981.

I Pasos. Introduzione, traduzione e note a cura di E. Cancelliere. Roma: Bulzoni, 1986.

Pasos completos. Ed. J. M. Marin. Madrid: Espasa Calpe, 1990.

Pasos. Ed. J. L. Canet, Madrid: Castalia, 1992. 